\title{
OMAE2020-18027
}

\section{INFLUENCE OF COMBINED EMPIRICAL FUNCTIONS ON SLUG FLOW PREDICTIONS OF PIPELINES WITH VARIABLE INCLINATIONS}

\author{
Hossein Zanganeh, Victoria Kurushina, Narakorn Srinil* \\ School of Engineering, Newcastle University, \\ Newcastle upon Tyne, UK
}

\author{
Omar K. Matar \\ Department of Chemical Engineering, \\ Imperial College London, UK
}

\begin{abstract}
Prediction of internal multiphase flows in subsea pipelines is an integral part of the oil and gas production system design. High mass and pressure fluctuations are often encountered during the operation with a liquid-gas slug flow regime exhibiting a sequence of long gas bubbles and aerated liquid slugs. It is important for industry to realistically identify the slug flow occurrence and predict slug flow characteristics, depending on several multiphase flow-pipe parameters. These may be achieved using a one-dimensional, steady-state, mechanistic model accounting for a mass and momentum balance of the two liquid-gas fluids within a controlled volume often referred to as a slug unit. By reducing a 3-D flow problem to a 1-D one, several empirical or closure correlations and associated empirical coefficients have been introduced in the literature and used in commercial software predicting slug flows in subsea jumpers, pipelines and risers with variable inclinations.

This study aims to investigate the influence of combined 25 closure functions on the predictions of slug flows in horizontal and inclined pipes based on a steady-state mechanistic model for a wide range of superficial liquid and gas velocities. The model with studied closures is implemented by the authors of this study as the numerical tool iSLUG. The model performance is verified with respect to the estimated film liquid holdup, film length and pressure drop per length of a slug unit for an empirically specified translational velocity, slug liquid holdup, slug liquid length and pipe wall wettability. Closure combinations are analyzed using the relative performance factors and compared against available experimental data in order to identify a set of functions suitable for upward, downward and horizontal flows, and the effect of diameter and inclination on the model prediction is considered. The present method and analysis outcomes may further contribute to the improvement of transient liquid-gas flow models to predict more practical cases.
\end{abstract}

\section{INTRODUCTION}

Slug flow may lead to a flow-induced vibration problem in subsea production systems due to the large pressure fluctuations caused by a sequence of turbulent long gas bubbles and liquid slugs [21]. A steady-state mechanistic slug flow model has an advantage of reducing the computational time when compared to transient flow simulations. For mechanistic models, empirical correlations are used to simplify the 3-D complex phenomenon to 1-D flow characteristics [8]. Around 11 types of correlations are currently in use (e.g., see [29]). Several studies considered the relative accuracy of 3 to 11 empirical correlations applied to the basic model $[11,29,36]$ or separately to the experimental data [35]. These studies have focused on slug and stratified flows in a horizontal pipe, recommending the optimal sets of closures to improve the prediction accuracy. It is admitted by the authors that overall numerical results obtained are dependent on the benchmarked experimental data. An identification of empirical correlations or closures appropriate for inclined pipes has been attempted in [11], but no recommendations were given due to the observed substantial errors.

Attention of this paper is paid on analyzing the performance of four types of correlations and their combinations applied to the basic model from [43] in order to model a straight pipe with variable 14 inclinations. Employed experimental data are based on two theses at the University of Tulsa: results for upward inclinations from $0^{\circ}$ to $80^{\circ}$ [14] and downward inclinations from $0^{\circ}$ to $-30^{\circ}$ [37]. Some governing equations of the mechanistic model developed in [43] are considered and incorporated into the in-house tool nicknamed iSLUG [41]. Details of experimental data and methodologies for model performance assessment are explained. Comments on the applicability of closure functions for the rigid pipe with variable inclinations subject to different superficial liquid-gas velocities are provided. A sensitivity study is performed. The paper ends with some conclusions.

*Corresponding author: narakorn.srinil@newcastle.ac.uk 


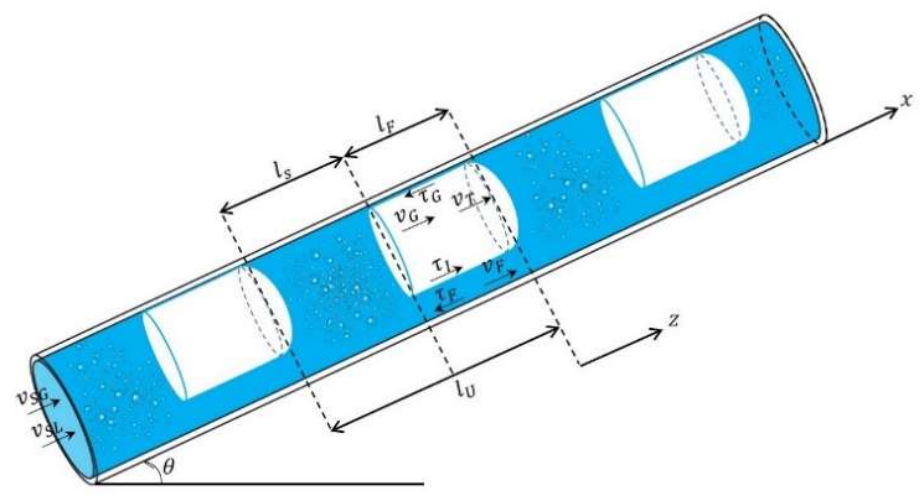

FIGURE 1: STEADY-STATE SLUG FLOW MODEL

\section{MECHANISTIC MODEL}

A 'unified' mechanistic gas-liquid slug flow model accounts for a flow pattern transition in a straight pipe with variable inclination angles [6]. A set of governing equations and empirical expressions are applied to each flow pattern. The same mass and momentum equations may be applicable to all flow regimes [42]. In this study, the unified mechanistic model in [43], which allows predicting the steady-state slug flow variables, is considered by assuming that the slug flow is fully developed.

A slug unit cell is shown in Fig. 1. The slug unit travels at the translational velocity $\boldsymbol{v}_{T}$, with the unit length $L_{U}$, the slug liquid length $L_{S}$ and the liquid film length $L_{F}$. The slug liquid zone has the liquid holdup $H_{L S}$ whereas the film zone has the liquid holdup $H_{L F}$. By assuming a no-slip condition, the liquid and gas flow velocities in the film zone are denoted as $v_{F}$ and $v_{G}$, respectively. This unified model accounts for the interfacial and wall shear stresses acting in the film zone, but neglects variations of the hydrostatic pressure related to the changes in the film height as in [13], [23] and [31]. The effect of hydrostatic pressure on the film shape was considered in [39] and [42]. In [43], a single combined momentum equation is solved for the entire film zone being a control volume.

Both liquid and gas are assumed to be incompressible [43] such that the associated fluid densities remain as constants regardless of the pressure change. The combined continuity equation for the liquid film and the gas pocket for the fully developed slug flow in [43] is

$$
v_{S}=H_{L F} v_{F}+\left(1-H_{L F}\right) v_{G},
$$

where $\boldsymbol{v}_{\boldsymbol{S}}$ is the mixture velocity. The combined momentum equation for the entire liquid film zone is given by

$$
\begin{gathered}
\frac{\rho_{L}\left(v_{T}-v_{F}\right)\left(v_{S}-v_{F}\right)-\rho_{G}\left(v_{T}-v_{G}\right)\left(v_{S}-v_{G}\right)}{L_{F}} \\
-\frac{\tau_{F} S_{F}}{H_{L F} A}+\frac{\tau_{G} S_{G}}{\left(1-H_{L F}\right) A}+\tau_{I} S_{I}\left(\frac{1}{H_{L F} A}+\frac{1}{\left(1-H_{L F}\right) A}\right) \\
-\left(\rho_{L}-\rho_{G}\right) g \sin \theta=0 .
\end{gathered}
$$

Here, $A$ is the internal cross-sectional area of the pipe, $g$ is the gravitational acceleration, $\theta$ is the pipe inclination, $\rho_{L}$ and $\rho_{G}$ are the liquid and gas densities, $\tau_{I}$ is the interfacial shear stress, $\tau_{F}$, and $\tau_{G}$ are the wall shear stresses in the liquid film and the gas pocket, $S_{I}, S_{F}$, and $S_{G}$ are the perimeters at the liquid and gas interface, film zone and gas pocket, respectively. The first lefthand side term in Eq. (2) is the momentum exchange between the slug body and the film region as a result of considering the entire film zone as a control volume.

The main outputs from Eq. (1)-(2) are the film liquid holdup $H_{L F}$, the liquid velocity in the film $v_{F}$, the gas velocity in the film $v_{G}$ and the film length $L_{F}$. Other variables (slug liquid holdup $H_{L S}$, slug length $L_{S}$, translational velocity $v_{T}$ and shear stresses) are evaluated through the empirical closure correlations. When accounting for a single unknown variable $L_{F}$, Eq. (2) may be reduced to an algebraic equation:

$$
\begin{gathered}
\frac{H_{L S} \rho_{L} v_{T}\left(L_{F}+L_{S}\right)\left(v_{S}-v_{T}\right)^{2}\left(v_{S L}-H_{L S} v_{S}\right)}{K_{2}{ }^{2}} \\
-\frac{\rho_{G} v_{T}\left(L_{F}+L_{S}\right)\left(H_{L S}-1\right)\left(v_{S}-v_{T}\right)^{2}\left(v_{S L}-H_{L S} v_{S}\right)}{K_{1}^{2}} \\
+\tau_{I} S_{I}\left(\frac{L_{F} v_{T}}{A K_{1}}-\frac{L_{F} v_{T}}{A K_{2}}\right)+\frac{S_{F} L_{F} \tau_{F} v_{T}}{A K_{2}}+\frac{S_{G} L_{F} \tau_{G} v_{T}}{A K_{1}} \\
+\left(\rho_{L}-\rho_{G}\right) g \sin \theta=0,
\end{gathered}
$$

where $\boldsymbol{v}_{\boldsymbol{S} \boldsymbol{L}}$ and $\boldsymbol{v}_{\boldsymbol{S G}}$ are the superficial liquid and gas velocities, respectively, and

$$
\begin{gathered}
K_{1}=L_{F} v_{S L}-L_{F} v_{T}+L_{S} v_{S L}-H_{L S} L_{F} v_{S} \\
+H_{L S} L_{F} v_{T}-H_{L S} L_{S} v_{S}, \\
K_{2}=L_{F} v_{S L}+L_{S} v_{S L}-H_{L S} L_{F} v_{S}+H_{L S} L_{F} v_{T} \\
-H_{L S} L_{S} v_{S} .
\end{gathered}
$$

To solve Eq. (3), the empirical correlations for the slug liquid holdup, slug length, translational velocity and wetted wall fraction are required as presented in the next section. Interactions of the internal flow fluctuations with the pipe are not considered in this paper. These can be found, e.g., in Ma and Srinil [25].

\section{EMPIRICAL CORRELATIONS}

In this study, 4, 6, 4 and 11 empirical closure correlations for the translational velocity, slug length, wetted wall fraction and slug liquid holdup, respectively, are considered whose models are summarized in Table 1. For a given set of input parameters, a total of 1056 combinations based on such 25 correlations may be considered. Herein, each combination is named by using a row matrix, e.g., as $\{4,1,2,3\}$ in which each number (from the left to the right) is referred to the first to fourth columns in Table 1 , respectively. As an example, $\{4,1,2,3\}$ is the combination of correlations [34], [43], [20] and [16], respectively. It is worth noting that most closures in Table 1 are functions of $v_{S G}, v_{S L}$ and the inner diameter $D$ of the pipe, and 12 expressions account for the pipe inclination $\theta$. 


\section{ASSESSMENT METHODOLOGY}

For model comparisons, four sets of experimental data in [14] and [37] are considered as specified in Table 2, based on the air-kerosene flow in a 2-inch diameter pipe. Measured quantities in [14] include the film liquid holdup, film length and pressure drop per the slug unit length, whereas those in [37] are the pressure drop per the liquid slug length. The reported slug flow results in [37] are at higher superficial liquid velocities and for a wider range of superficial gas velocities than those in [14], while densities and viscosities are similar for both studies.

Following the methodology used in $[5,11]$, the performance of each correlation combination is assessed by evaluating the Relative Performance Factor (RPF) $F_{P R k}$ which accounts for the sum of changes in the relative and absolute errors:

$$
F_{P R k}=\sum_{n=1}^{6} \frac{\left|E_{n, k}\right|-\left|E_{n, k, \text { min }}\right|}{\left|E_{n, k, \text { max }}\right|-\left|E_{n, k, \text { min }}\right|},
$$

where $n$ is the error type number varying from 1 to $6, k$ is the closure combination number varying from 1 to 1056 , and $E_{1, k}$, $E_{2, k}, E_{3, k}, E_{4, k}, E_{5, k}$ and $E_{6, k}$ are the average percent error, the absolute average percent error, the percent standard deviation, the average error, the absolute average error and the standard deviation, respectively. These are expressed as follows:

$$
\begin{aligned}
& E_{1, k}=\left(\frac{1}{N} \sum_{i=1}^{N} \frac{y_{\text {model }, i}-y_{\text {exper }, i}}{y_{\text {exper }, i}}\right) \cdot 100 \%, \\
& E_{2, k}=\left(\frac{1}{N} \sum_{i=1}^{N}\left|\frac{y_{\text {model }, i}-y_{\text {exper }, i} \mid}{y_{\text {exper }, i}}\right|\right) \cdot 100 \% . \\
& E_{3, k}=\sum_{i=1}^{N} \sqrt{\frac{\left(\frac{y_{\text {model }, i}-y_{\text {exper }, i}}{y_{\text {exper }, i}}-\frac{E_{1, k}}{100}\right)^{2}}{(N-1)},} \\
& E_{4, k}=\left(\frac{1}{N} \sum_{i=1}^{N} y_{\text {model }, i}-y_{\text {exper }, i}\right), \\
& E_{5, k}=\left(\frac{1}{N} \sum_{i=1}^{N}\left|y_{\text {model }, i}-y_{\text {exper }, i}\right|\right) \cdot 100 \%,
\end{aligned}
$$

$$
E_{6, k}=\sum_{i=1}^{N} \sqrt{\frac{\left(y_{\text {model }, i}-y_{\text {exper }, i}-E_{4, k}\right)^{2}}{(N-1)}},
$$

where $i$ is the experimental case number varying from 1 to $N$ (total number of cases as specified in Table 2), $y_{\text {model, } i}$ is the value predicted by the model $k$ in the experimental case $i$, and $y_{\text {exper }, i}$ is the associated experimental data. The absolute minimum and maximum values of errors in Eq. (6) are denoted by $E_{n, k, \min }=\min \left\{E_{n, k}\right\}$ and $E_{n, k, \max }=\max \left\{E_{n, k}\right\}$.

Herein, the liquid film length and pressure drop (outputs) for case studies in Table 2 are first calculated using 1056 closure combinations. Errors $E_{n, k}$ in Eqs. (7)-(12) are computed for each output, each closure combination and each set of experimental data. RPFs are then computed based on the six types of errors $E_{n, k}$. As an example, a single RPF for upward flows (8 positive inclinations) is calculated for each closure combination based on 9 data points per angle (i.e. $N=72$ ). The minimum value of 1056 RPFs, $\min \left\{F_{P R k}\right\}$, is identified and used for selecting the most optimal combination of closures for each output and set of input flow-pipe parameters.

\section{SELECTION OF EMPIRICAL CORRELATIONS}

Applicable closure combination models are selected based on the solution convergence rates combining four different groups of $\theta$ (upward, downward and horizontal flows) when compared with experimental data. Figure 2 presents the sample statistics of closure correlations in the converged models.

Here, the empirical relationship for the slug length derived in [43] appears suitable for all considered inclination angles, as seen in Figs $2 b, f, j$ and $n$. A preference for the translational velocity expression proposed in [34] is indicated for upward flows in Fig. 2a, whereas data for other pipe inclinations show a relatively similar applicability for all four variables (Figs 2c, i and $\mathrm{m})$. Correlations from $[13,20]$ for the wetted wall fraction perform well for positive $\theta$ (Fig. 2c), correlations from [20,22] suitable for $\theta=0$ (Figs $2 \mathrm{~g}$ and $\mathrm{k}$ ), and the correlation from [28] covers negative $\theta$ (Fig. 2o). The horizontal flow case in Figs $2 \mathrm{~h}$

\begin{tabular}{|c|c|c|c|}
\hline Translational velocity & Slug length & Wetted wall fraction & Slug liquid holdup \\
\hline 1. Nicklin et al. [32] & 1. Zhang et al. [43] & 1. Hart et al. [22] & 1. Gregory et al. [19] \\
\hline 2. Bendiksen [9] & 2. Brill et al. [10] & 2. Grolman and Fortuin [20] & 2. Malnes [26] \\
\hline 3. Théron [40] & 3. Norris [33] & 3. Meng [28] & 3. Ferschneider [16] \\
\hline \multirow[t]{7}{*}{ 4. Petalas and Aziz [34] } & 4. Gordon and Fairhurst [18] & 4. Fan $[12]$ & 4. Barnea and Brauner [7] \\
\hline & 5. Scott et al. [38] & & 5. Andreussi and Bendiksen [4] \\
\hline & 6. Al-Safran et al. [2] & & 6. Marcano et al. [27] \\
\hline & & & 7. Abdul-Majeed [1] \\
\hline & & & 9. Kora et al. [24] \\
\hline & & & 10. Al-Safran et al. [3] \\
\hline & & & 11. Zhang et al. [43] \\
\hline
\end{tabular}
and $\mathrm{i}$ indicate a good performance for the slug liquid holdup closure from [43]. Closures from [19,43] are preferred for downward flows, according to Fig. 2p. The slug liquid holdup for upward flows (Fig. 2d) can be predicted by eight different closure expressions.

TABLE 1: EMPIRICAL CORRELATIONS OF CONSIDERED FOUR VARIABLES IN MECHANISTIC SLUG FLOW MODEL 
TABLE 2: CONSIDERED FLOW-PIPE PARAMETERS [14,37]

\begin{tabular}{|c|c|c|}
\hline Parameters & $\begin{array}{c}\text { Felizola } \\
(1992) \\
\end{array}$ & $\begin{array}{c}\text { Roumazeilles } \\
\text { (1994) }\end{array}$ \\
\hline Pipe inner diameter, $D[\mathrm{~m}]$ & 0.0508 & 0.0508 \\
\hline Pipe length, $L[\mathrm{~m}]$ & 15 & 19.8 \\
\hline Range of inclinations, $\Theta[\mathrm{deg}]$ & 0 to 80 & 0 to -30 \\
\hline $\begin{array}{l}\text { Range of superficial liquid } \\
\text { velocities, } v_{S L}[\mathrm{~m} / \mathrm{s}]\end{array}$ & $0.05-0.56$ & $0.91-2.44$ \\
\hline $\begin{array}{l}\text { Range of superficial gas } \\
\text { velocities, } v_{S G}[\mathrm{~m} / \mathrm{s}]\end{array}$ & $0.4-2.02$ & $0.91-9.36$ \\
\hline $\begin{array}{l}\text { Liquid density range, } \rho_{L} \\
{\left[\mathrm{~kg} / \mathrm{m}^{3}\right]}\end{array}$ & 798.6-810.0 & $801.2-809.8$ \\
\hline Gas density range, $\rho_{G}\left[\mathrm{~kg} / \mathrm{m}^{3}\right]$ & $2.09-2.91$ & $0.76-2.12$ \\
\hline $\begin{array}{l}\text { Liquid dynamic viscosity } \\
\text { range, } \mu_{L}\left[10^{-3} \mathrm{~kg} /\left(\mathrm{m}^{*} \mathrm{~s}\right)\right]\end{array}$ & $1.3-1.7$ & $1.4-1.7$ \\
\hline $\begin{array}{l}\text { Gas dynamic viscosity } \\
\text { range, } \mu_{G}\left[10^{-5} \mathrm{~kg} /\left(\mathrm{m}^{*} \mathrm{~s}\right)\right]\end{array}$ & $1.8-1.9$ & 1.9 \\
\hline \multirow[t]{2}{*}{$\begin{array}{l}\text { Number of available data } \\
\text { points \& available quantities }\end{array}$} & $\begin{array}{c}\text { Group 1 } \\
N=72 \text { points } \\
\text { for positive } \\
\text { inclinations } \\
\text { for } \\
\text { 1) film length, } \\
\text { 2) film liquid } \\
\text { holdup, } \\
\text { 3) pressure } \\
\text { drop per slug } \\
\text { unit length } \\
\text { (except angle } \\
\text { of 30 degrees) }\end{array}$ & $\begin{array}{c}\text { Group } 2 \\
N=79 \text { points } \\
\text { for negative } \\
\text { inclinations for } \\
\text { 1) pressure drop } \\
\text { per length of } \\
\text { liquid slug }\end{array}$ \\
\hline & $\begin{array}{l}\text { Group } 3 \\
N=9 \text { points } \\
\text { for horizontal } \\
\text { position for } \\
\text { 1) film length, } \\
\text { 2) film liquid } \\
\text { holdup }\end{array}$ & $\begin{array}{c}\text { Group } 4 \\
N=34 \text { points } \\
\text { for horizontal } \\
\text { position } \\
\text { 1) pressure drop } \\
\text { per length of } \\
\text { liquid slug }\end{array}$ \\
\hline
\end{tabular}

The analysis of convergence rates indicates the importance of combining specific closures for the translational velocity, slug length and wetted wall fraction for positive inclinations, and that of combining specific closures for the wetted wall fraction and slug length for negative inclinations. Horizontal flow predictions require specific correlations for the slug length, liquid holdup, translational velocity and wetted wall fraction.

Note that correlations from $[12,20,28,34]$ and [43] may be most applicable to inclined pipes, accounting for $\theta$. Closures for the translational velocity by [34] and for the slug liquid holdup by [43] depend on several key input parameters, which may help improving the inclined slug flow feature predictions.

Closure combinations are selected from the list of converged models according to the increasing RPFs for each flow variable as presented in Table 3. RPFs for three variables of upward flows are visualized in Fig. 3. Empirical functions with suitable RPFs for several experimental datasets selected based on errors and corresponding RPFs are provided in Table 4.

According to Fig. 3 and Table 3, the closure combinations $\{4,1,2,3\},\{4,1,2,5\},\{4,1,2,10\},\{4,1,2,6\}$ and $\{4,1,2,9\}$ have the least RPFs among the converged models for all three flow variables and for the upward inclination. They combine closures from [34] for the translational velocity, [43] for the slug length and [20] for the wetted wall fraction noted previously during the analysis of Fig. 2.

Tables 4 and 5 illustrate that the least RPFs for horizontal flows, (a) based on data in [14], belong to the combinations $\{3,1,3,11\},\{3,1,1,3\}$ and $\{3,1,4,11\}$, and, (b) based on data in [37], belong to the combinations $\{4,3,3,11\},\{4,2,4,11\}$ and $\{4,5,2,11\}$. The model with combined correlations $\{4,1,3,11\}$ is found applicable for both horizontal and downward flows up to the inclination of -30 degrees, according to the comparisons with data in [37].

Table 4 illustrates that it is unfeasible to select a combination applicable for both upward and downward inclinations or for both horizontal flows, in part due to the observed limited model convergence. This also implies that, for a narrower group of angles or a reduced number of experimental data points, there may exist the better combinations of closures with the improved accuracy and lower RPFs. The following section demonstrates and compare capability and applicability of the selected closure combinations.

\section{EFFECT OF DIAMETER AND INCLINATION}

Empirical expressions and their combinations affect not only the slug flow characteristics but also on the slug flow transition. For upward inclinations, the selected model combinations $\{4,1,2,3\}$, $\{4,1,2,5\},\{4,1,2,6\},\{4,1,2,10\}$ differ only in the expression for the slug liquid holdup. Figure 4 illustrates significant differences in the predicted slug flow borders in the parametric plane of the superficial gas and liquid velocities predicted. The combination $\{4,1,2,10\}$ in Fig. 4d predicts the largest slug flow zone with the upper border of the superficial liquid velocity around $5 \mathrm{~m} / \mathrm{s}$ and the superficial gas velocity around $20 \mathrm{~m} / \mathrm{s}$. In contrast, the slug flow range predicted by the combination $\{4,1,2,3\}$ in Fig. $4 \mathrm{a}$ is the smallest, limited by the superficial liquid velocity below 3 $\mathrm{m} / \mathrm{s}$ and the superficial gas velocity around $12 \mathrm{~m} / \mathrm{s}$. Therefore, it may be suggested that the slug liquid holdup expression has a significant influence on the slug zone transition prediction.

With the model [43], a limit on the number of maximum iterations to arrive at a converged solution of the combined momentum equation is required. This limit in the present study is set to be 200 diameters for the film length. Accordingly, the maximum film length of about 150-200 diameters is observed in Fig. 4 at the southern border of the slug zone. This maximum value is achieved by decreasing (increasing) the superficial liquid (gas) velocity. The predicted minimum film length (nearly 0 ) occurs with increasing (decreasing) superficial liquid (gas) velocity for all the selected models.

The combination $\{4,1,2,10\}$ for upward flows is tested on the sensitivity to the pipe diameter and inclination variations in Fig. 5. For comparison purposes, the slug flow borders in this figure are obtained using the $2 \mathrm{D}$ statistical filtering with the radius of 2.3. Fig. $5 \mathrm{~b}$ illustrates a noticeable effect of increasing the pipe diameter, which leads to a relatively proportional growth of the 
Translational velocity

(a)
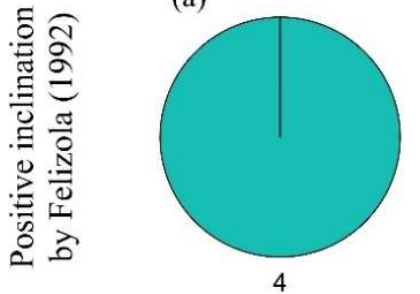

(e)

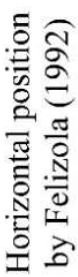

4

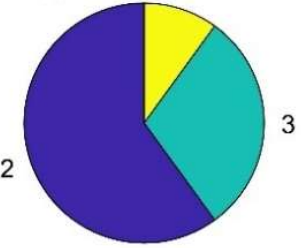

(i)
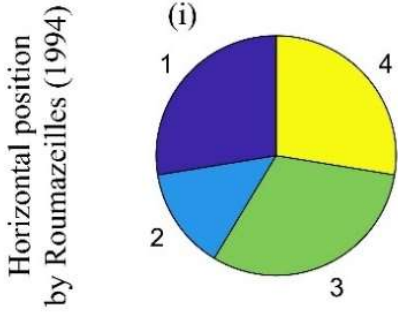

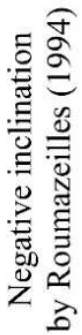

Slug length

(b)

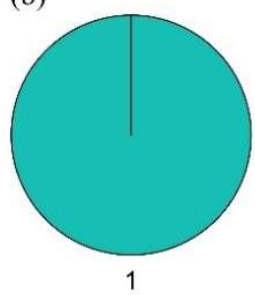

(f)

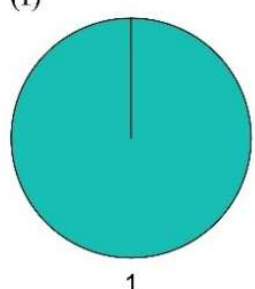

(j)

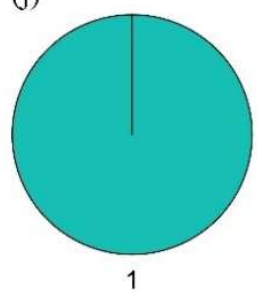

(n)

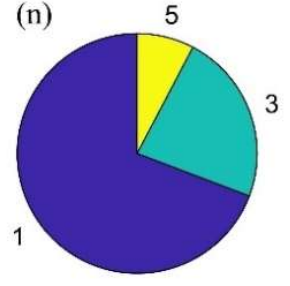

Wetted Wall Fraction

(c)

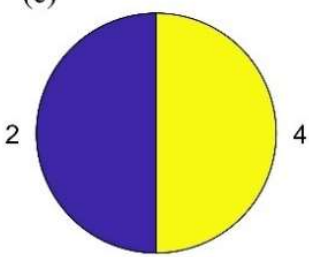

(g)

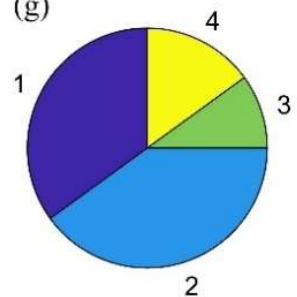

(k)

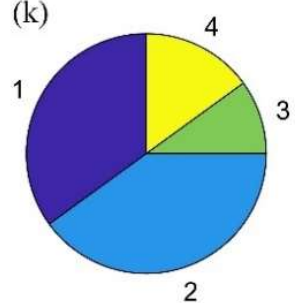

(o)

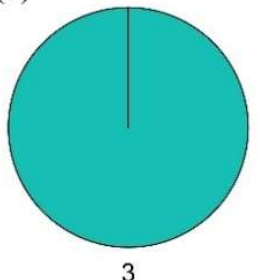

Slug liquid holdup

(d)

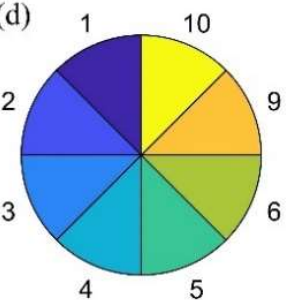

(h)

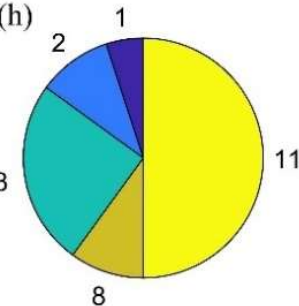

(1)

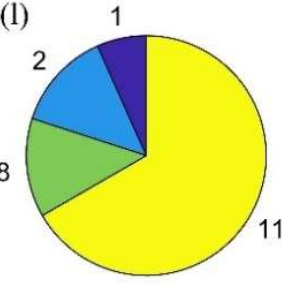

(p)

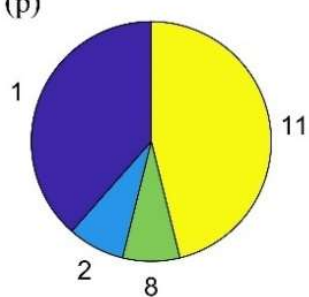

FIGURE 2: STATISTICS OF CLOSURES IN CONVERGED MODELS FOR DATA [14,37] WITH SECTORIAL LABEL INDICES (1-11) CORRESPONDING TO CLOSURE NUMBERS IN TABLE 1

predicted slug flow occurrence in both the superficial liquid and gas velocity ranges. The growth of the inclination in Fig. 5a leads to a different effect on the model prediction with the borders shrinking in terms of the superficial liquid velocity.

Variation and comparison of four flow characteristics for the pipe diameter of $0.05 \mathrm{~m}$ and inclination of $45^{\circ}$ is shown in Fig. 6. The slug liquid holdup in Fig. 6a has the minimum values around $0.70-0.75$ at $V_{S G}$ above $15 \mathrm{~m} / \mathrm{s}$ and approaches the value of 1 as the superficial velocities are close to 0 . The film liquid holdup in Fig. $6 \mathrm{~b}$ is above 0.7 at the $V_{S G}$ below $2 \mathrm{~m} / \mathrm{s}$, while the major part of the slug zone has the values of $H_{L F}$ below 0.3 . The pressure drop per slug unit is generally below $20 \mathrm{kPa} / \mathrm{m}$ and declines with the decreasing superficial velocities, as illustrated in Fig. 6c. A rapid increase of the pressure drop is observed in the range of $V_{S G}$ from 15 to $20 \mathrm{~m} / \mathrm{s}$, where transition to other regimes is taking place. The slug frequency in Fig. 6d is much more sensitive to the superficial liquid velocity than to the superficial gas velocity. Here, the frequency higher than $5 \mathrm{~Hz}$ is observed above $V_{S L}=7 \mathrm{~m} / \mathrm{s}$, and values lower than $1 \mathrm{~Hz}$ are predicted below $V_{S L}=0.5 \mathrm{~m} / \mathrm{s}$. This result is qualitatively consistent with the observations in [30] for the slug frequency variation at the fixed superficial gas velocity. 
(a)

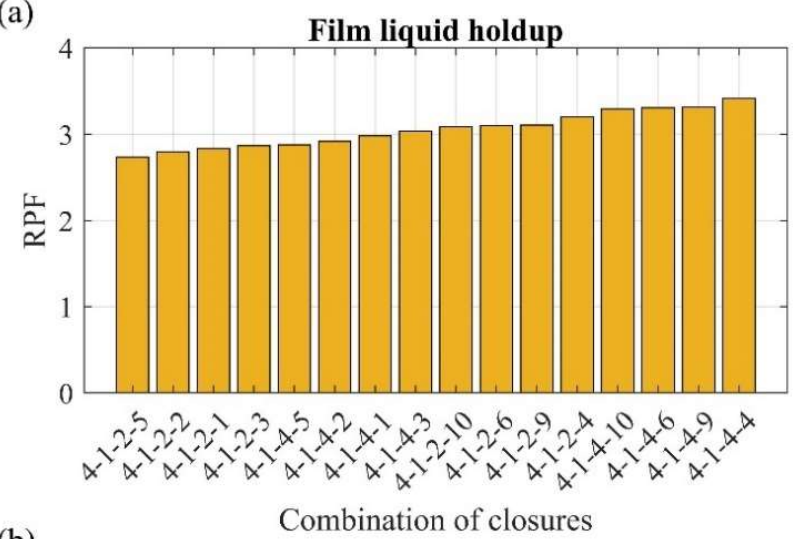

(b)

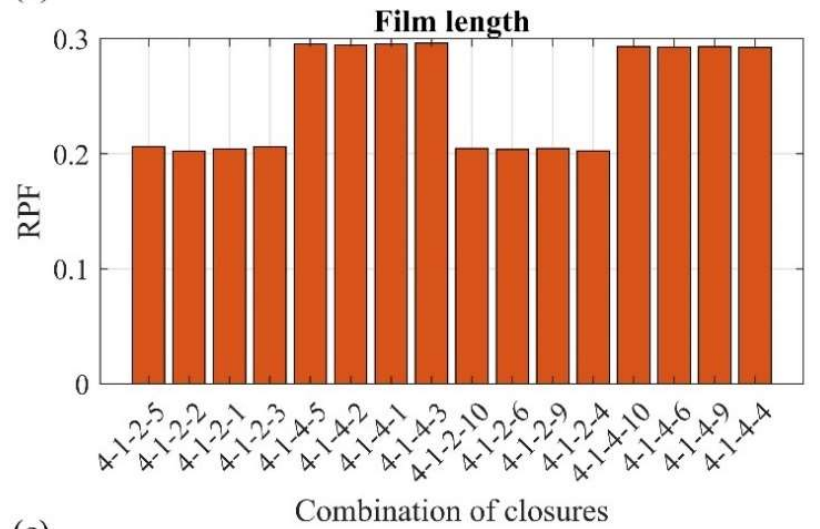

(c)

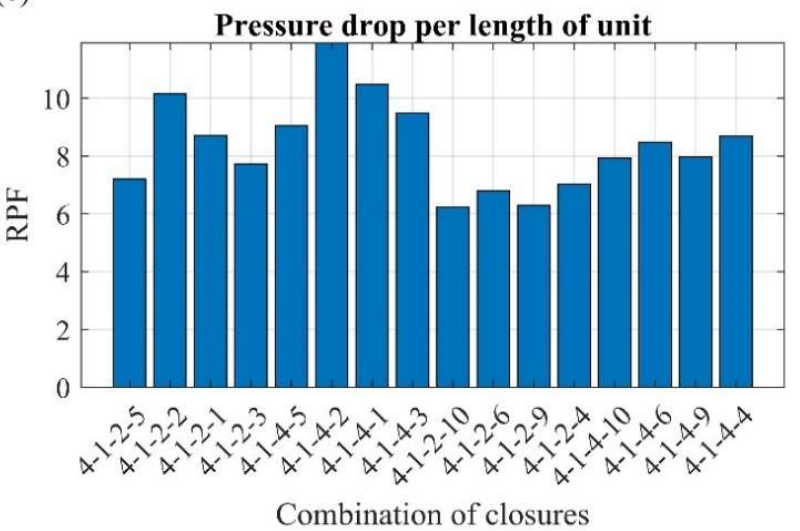

FIGURE 3: RPFS OF 3 PREDICTED FLOW VARIABLES BASED ON 16 CONVERGED MODELS FOR 8 UPWARD INCLINATIONS [14]: (A) FILM LIQUID HOLDUP, (B) FILM LENGTH, AND (C) PRESSURE DROP PER SLUG UNIT LENGTH

\section{CONCLUSIONS}

The effects of closure combinations on the prediction of slug flow characteristics in inclined pipes have been investigated using a one-dimensional mechanistic steady-state slug flow model. The selected combinations show the best solution convergence for all relevant experimental data points and the lowest relative performance factors. For the studied range of the superficial liquid and gas velocities, one closure combination may be recommended for horizontal and downward flows whereas up to five combinations may be applicable to upward flows. Most of the selected correlations are dependent on the pipe inclination, and these may be used in combination with other correlations independent of the pipe inclination. Based on the sensitivity studies of the selected closure combinations, the slug frequency is found to be dependent mainly on the superficial liquid velocity, while the pressure drop and film liquid holdup are more sensitive to the superficial gas velocity. The slug flow regime and transition also depend on the combined effect of closures. Empirical functions and their combinations applicable to transient slug flow simulations should be further investigated.

\section{ACKNOWLEDGEMENTS}

The authors are grateful for the funding support from the Engineering and Physical Sciences Research Council (EPSRC) of UK Research and Innovation through the "MUltiphase Flowinduced Fluid-flexible structure InteractioN in Subsea applications (MUFFINS)" project grants EP/P033148/1 and $\mathrm{EP} / \mathrm{P} 033180 / 1$

\section{REFERENCES}

[1] Abdul-Majeed, G.H. (2000). Liquid slug holdup in horizontal and slightly inclined two-phase slug flow. Journal of Petroleum Science and Engineering, 27(1-2), 27-32.

[2] Al-Safran, E., Gokcal, B., Sarica, C. (2011). High viscosity liquid effect on two-phase slug length in horizontal pipes. In $15^{\text {th }}$ International Conference on Multiphase Production Technology. BHR Group.

[3] Al-Safran, E., Kora, C., \& Sarica, C. (2013). Prediction of liquid volume fraction in slugs in two-phase horizontal pipe flow with high viscosity liquid. In 16th International Conference on Multiphase Production Technology. BHR Group.

[4] Anreussi, P., Bendiksen, K. (1989). An investigation of void fraction in liquid slugs for horizontal and inclined gas liquid pipe flow. International Journal of Multiphase Flow, 15(6), 937-946.

[5] Ansari, A. M., Sylvester, N. D., Shoham, O., \& Brill, J. P. (1990). A comprehensive mechanistic model for upward twophase flow in wellbores. In Annual Technical Conference and Exhibition. SPE.

[6] Barnea, D. (1987). A unified model for predicting flowpattern transitions for the whole range of pipe inclinations. International Journal of Multiphase Flow, 13(1), 112.

[7] Barnea, D., \& Brauner, N. (1985). Holdup of the liquid slug in two phase intermittent flow. International Journal of Multiphase Flow, 11(1), 43-49.

[8] Bendiksen, K. H., Malnes, D., Moe, R., \& Nuland, S. (1991). The Dynamic Two-Fluid Model OLGA: Theory and Application. SPE Production Engineering, 6(2), 171-180.

[9] Bendiksen, K. H. (1984). An experimental investigation of the motion of long bubbles in inclined tubes. International Journal of Multiphase Flow, 10(4), 467-483. 
TABLE 3: COMBINATIONS OF EMPIRICAL FUNCTIONS BASED ON RPFS FOR DIFFERENT FLOW DIRECTIONS

\begin{tabular}{|c|c|c|c|c|}
\hline Group & Variables & $\begin{array}{c}\text { Flow } \\
\text { direction }\end{array}$ & $\begin{array}{c}\text { Number of data } \\
\text { points }\end{array}$ & Combinations \\
\hline \multicolumn{5}{|c|}{ First few combinations listed by increasing RPFs } \\
\hline \multirow{3}{*}{1} & $H_{L F}$ & Upward & $\begin{array}{l}72 \text { points by } \\
\text { Felizola }(1992)\end{array}$ & $\begin{array}{l}\{4,1,2,5\},\{4,1,2,2\},\{4,1,2,1\},\{4,1,2,3\},\{4,1,4,5\},\{4,1,4,2\}, \\
\{4,1,4,1\},\{4,1,4,3\},\{4,1,2,10\},\{4,1,2,6\},\{4,1,2,9\}\end{array}$ \\
\hline & $L_{F}$ & Upward & $\begin{array}{l}72 \text { points by } \\
\text { Felizola (1992) }\end{array}$ & $\begin{array}{l}\{4,1,2,2\},\{4,1,2,4\},\{4,1,2,6\},\{4,1,2,1\},\{4,1,2,9\},\{4,1,2,10\} \\
\{4,1,2,3\},\{4,1,2,5\}\end{array}$ \\
\hline & $d P / d L_{U}$ & Upward & $\begin{array}{l}72 \text { points by } \\
\text { Felizola (1992) }\end{array}$ & $\begin{array}{l}\{4,1,2,10\},\{4,1,2,9\},\{4,1,2,6\},\{4,1,2,4\},\{4,1,2,5\},\{4,1,2,3\}, \\
\{4,1,4,10\},\{4,1,4,9\}\end{array}$ \\
\hline 2 & $d P / d L_{S}$ & Downward & $\begin{array}{l}79 \text { points by } \\
\text { Roumazeilles } \\
\text { (1994) }\end{array}$ & $\begin{array}{l}\{4,1,3,11\},\{1,5,3,11\},\{1,3,3,11\},\{3,3,3,11\},\{2,3,3,1\}, \\
\{1,1,3,11\},\{3,1,3,11\}\end{array}$ \\
\hline \multirow{2}{*}{3} & $H_{L F}$ & Horizontal & $\begin{array}{l}9 \text { points by } \\
\text { Felizola (1992) }\end{array}$ & $\{3,1,1,11\},\{3,1,1,3\},\{3,1,2,11\},\{3,1,2,3\},\{3,1,3,11\},\{3,1,4,11\}$ \\
\hline & $L_{F}$ & Horizontal & $\begin{array}{l}9 \text { points by } \\
\text { Felizola (1992) }\end{array}$ & $\begin{array}{l}\{3,1,3,11\},\{3,1,1,3\},\{3,1,2,3\},\{2,1,1,2\},\{2,1,1,8\},\{2,1,2,2\}, \\
\{3,1,4,11\},\{2,1,2,8\},\{2,1,2,1\}\end{array}$ \\
\hline 4 & $d P / d L_{S}$ & Horizontal & $\begin{array}{l}34 \text { points by } \\
\text { Roumazeilles } \\
(1994)\end{array}$ & $\begin{array}{l}\{4,3,3,11\},\{4,2,4,11\},\{4,5,2,11\},\{3,3,3,11\},\{2,3,3,1\} \\
\{3,5,4,11\},\{3,2,4,11\},\{4,1,3,11\},\{3,5,2,11\},\{3,2,2,11\}\end{array}$ \\
\hline
\end{tabular}

TABLE 4: SELECTED CLOSURE COMBINATIONS AND THEIR RELATIVE PERFORMANCE FACTORS (RPFS)

\begin{tabular}{|c|c|c|c|c|c|c|c|c|c|c|}
\hline $\begin{array}{l}\text { Combi- } \\
\text { nation }\end{array}$ & Data source & Pipe position & Variable & E1 & E2 & E3 & E4 & E5 & E6 & RPF \\
\hline \multirow{2}{*}{$4,1,3,11$} & \multirow{2}{*}{$\begin{array}{c}\text { Roumazeilles, } \\
1994\end{array}$} & $\begin{array}{c}\text { Inclined with angles } \\
\text { of }-3,-5,-10,-20 \text {, } \\
-30 \text { degrees }\end{array}$ & $\begin{array}{l}\text { Pressure drop } \\
\text { per slug } \\
\text { length }\end{array}$ & 276.9 & 276.9 & 1.60 & 274.5 & 274.5 & 2.52 & 0.81 \\
\hline & & Horizontal & $\begin{array}{l}\text { Pressure drop } \\
\text { per slug } \\
\text { length }\end{array}$ & 92.88 & 96.68 & 0.70 & 159.66 & 171.51 & 7.19 & 1.53 \\
\hline$\{4,1,2,10\}$ & \multirow{21}{*}{$\begin{array}{c}\text { Felizola, } \\
1992\end{array}$} & \multirow{15}{*}{$\begin{array}{c}\text { Inclined with angles } \\
\text { of } 10,20,40,50,60 \text {, } \\
70,80 \text { degrees }\end{array}$} & \multirow{5}{*}{$\begin{array}{l}\text { Pressure drop } \\
\text { per unit } \\
\text { length }\end{array}$} & 26.34 & 26.34 & 0.0085 & 70.72 & 70.72 & 0.46 & 6.24 \\
\hline$\{4,1,2,9\}$ & & & & 26.20 & 26.20 & 0.0084 & 70.20 & 70.20 & 0.43 & 6.29 \\
\hline$\{4,1,2,6\}$ & & & & 25.09 & 25.09 & 0.0079 & 67.16 & 67.16 & 0.42 & 6.80 \\
\hline$\{4,1,2,5\}$ & & & & 24.43 & 24.43 & 0.0103 & 67.82 & 67.82 & 0.73 & 7.20 \\
\hline$\{4,1,2,3\}$ & & & & 22.92 & 22.92 & 0.0071 & 62.46 & 62.46 & 0.51 & 7.73 \\
\hline$\{4,1,2,10\}$ & & & \multirow{5}{*}{$\begin{array}{l}\text { Film liquid } \\
\text { holdup }\end{array}$} & -47.04 & 47.04 & 0.0064 & -13.58 & 13.58 & 0.107 & 3.09 \\
\hline$\{4,1,2,9\}$ & & & & -47.08 & 47.08 & 0.0066 & -13.59 & 13.59 & 0.108 & 3.11 \\
\hline$\{4,1,2,6\}$ & & & & -47.52 & 47.52 & 0.0065 & -13.71 & 13.71 & 0.108 & 3.10 \\
\hline$\{4,1,2,5\}$ & & & & -48.16 & 48.16 & 0.0033 & -13.83 & 13.83 & 0.092 & 2.74 \\
\hline$\{4,1,2,3\}$ & & & & -48.61 & 48.61 & 0.0044 & -13.97 & 13.97 & 0.098 & 2.87 \\
\hline$\{4,1,2,10\}$ & & & \multirow{5}{*}{ Film length } & 17.20 & 32.82 & 0.21 & 27.86 & 46.89 & 1.43 & 0.20 \\
\hline$\{4,1,2,9\}$ & & & & 17.17 & 32.82 & 0.21 & 27.86 & 46.88 & 1.43 & 0.20 \\
\hline$\{4,1,2,6\}$ & & & & 16.64 & 32.73 & 0.21 & 27.18 & 46.83 & 1.44 & 0.20 \\
\hline$\{4,1,2,5\}$ & & & & 15.99 & 32.77 & 0.21 & 25.43 & 47.34 & 1.47 & 0.21 \\
\hline$\{4,1,2,3\}$ & & & & 15.52 & 32.90 & 0.21 & 25.10 & 47.44 & 1.47 & 0.21 \\
\hline$\{3,1,1,3\}$ & & \multirow{6}{*}{ Horizontal } & \multirow{3}{*}{$\begin{array}{l}\text { Film liquid } \\
\text { holdup }\end{array}$} & -33.86 & 33.99 & 0.0313 & -11.18 & 11.22 & 0.15 & 3.83 \\
\hline$\{3,1,4,11\}$ & & & & -27.47 & 27.48 & 0.0275 & -8.72 & 8.72 & 0.13 & 4.43 \\
\hline$\{3,1,3,11\}$ & & & & -28.20 & 28.83 & 0.037 & -8.93 & 9.13 & 0.15 & 4.36 \\
\hline$\{3,1,1,3\}$ & & & \multirow{3}{*}{ Film length } & -15.58 & 26.21 & 0.104 & -72.17 & 78.98 & 2.55 & 0.27 \\
\hline$\{3,1,4,11\}$ & & & & -17.28 & 26.17 & 0.099 & -78.08 & 83.16 & 2.72 & 0.33 \\
\hline$\{3,1,3,11\}$ & & & & -15.68 & 24.00 & 0.094 & -68.48 & 73.26 & 2.43 & 0.23 \\
\hline
\end{tabular}


(a)

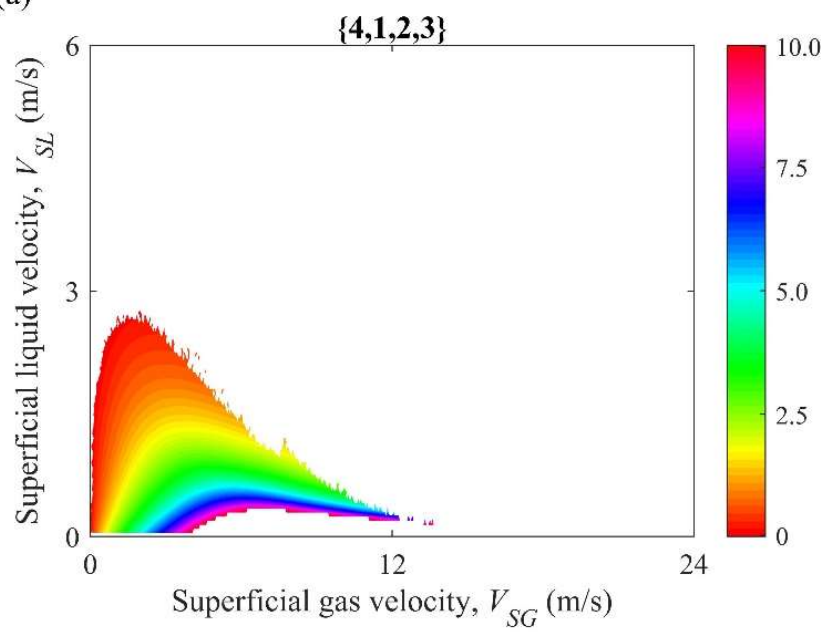

(c)

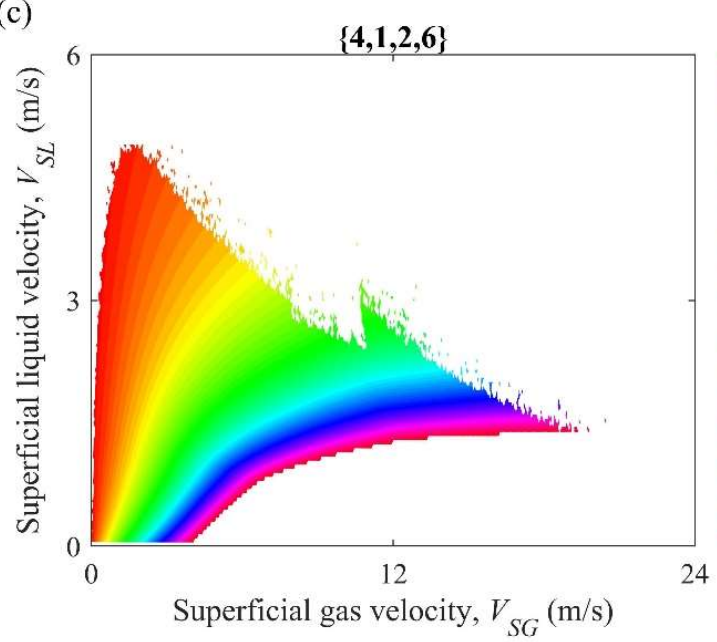

(b)

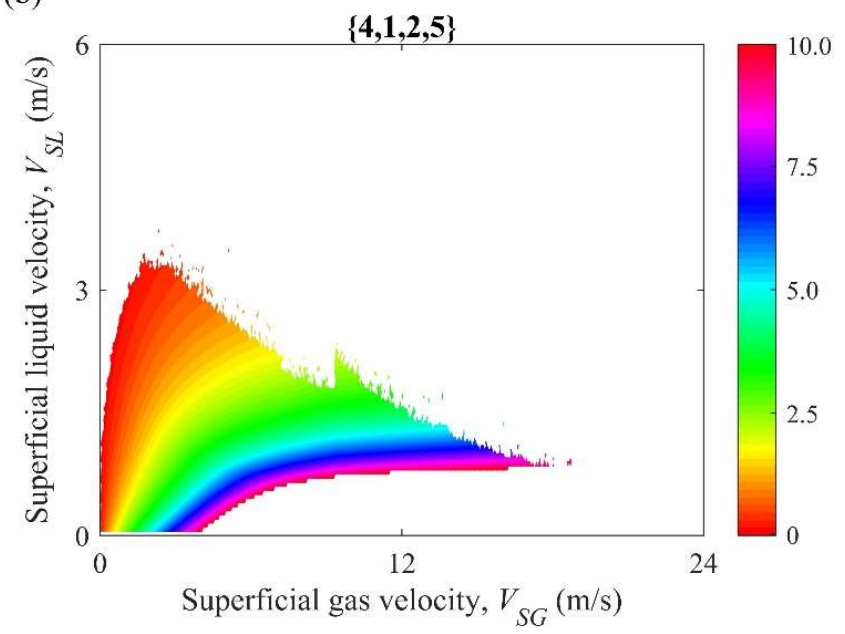

(d)

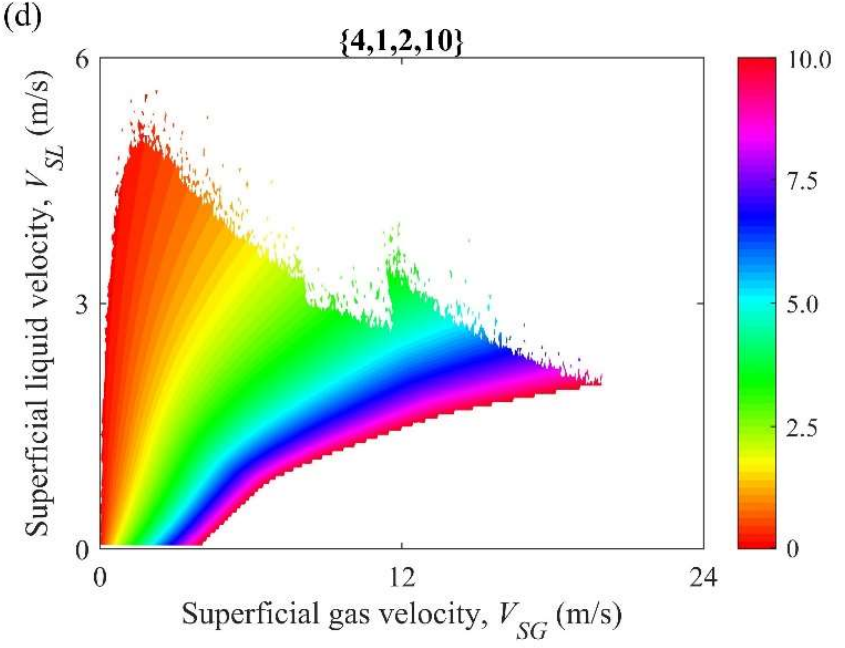

FIGURE 4: VARIATION OF FILM LENGTH (M) PREDICTED FOR PIPE DIAMETER OF 0.05 M AND INCLINATION OF 45 DEGREES BY CLOSURES: (A) $\{4,1,2,3\}$, (B) $\{4,1,2,5\}$, (C) $\{4,1,2,6\}$, (D) $\{4,1,2,10\}$

(a)

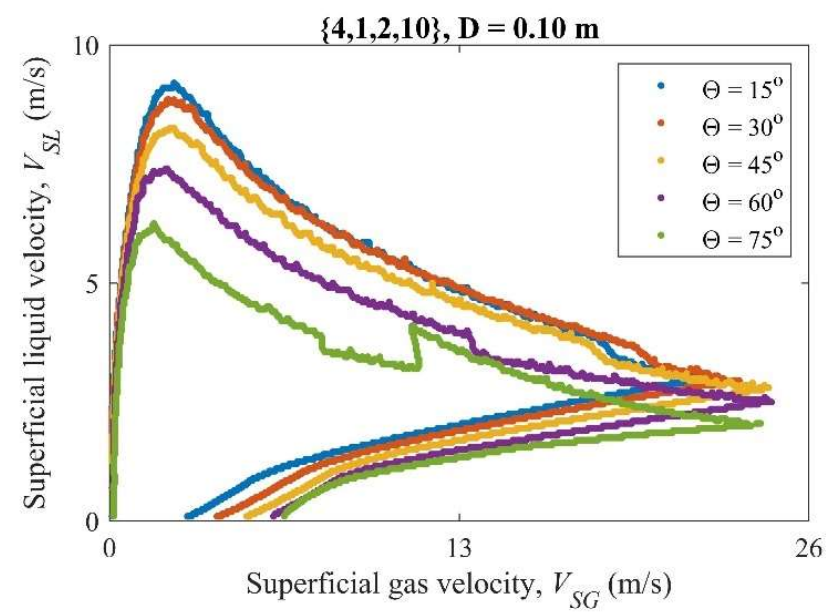

(b)

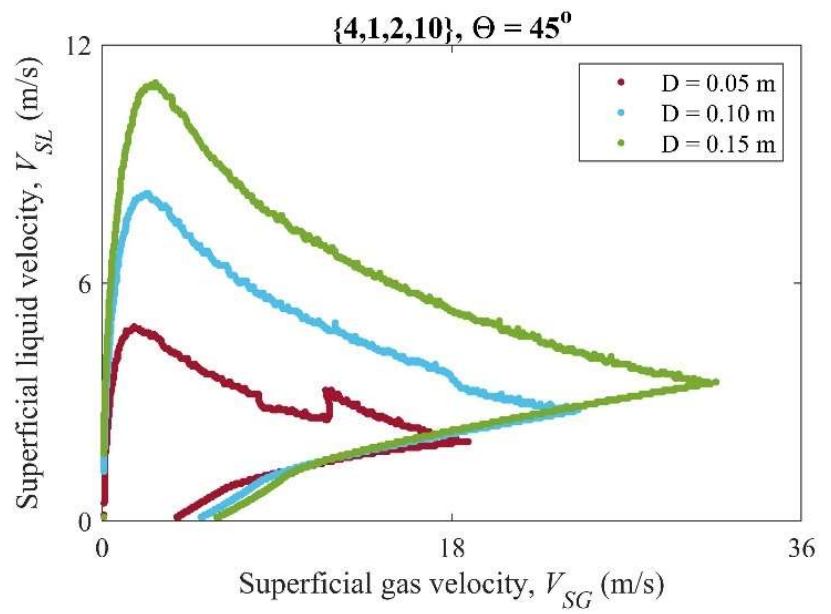

FIGURE 5: SLUG FLOW BORDERS PREDICTED WITH CLOSURES $\{4,1,2,10\}$ FOR: (A) 5 INCLINATION CASES AT DIAMETER OF 0.10 M, (B) 3 DIAMETER CASES AT INCLINATION OF 45 DEGREES 
(a)

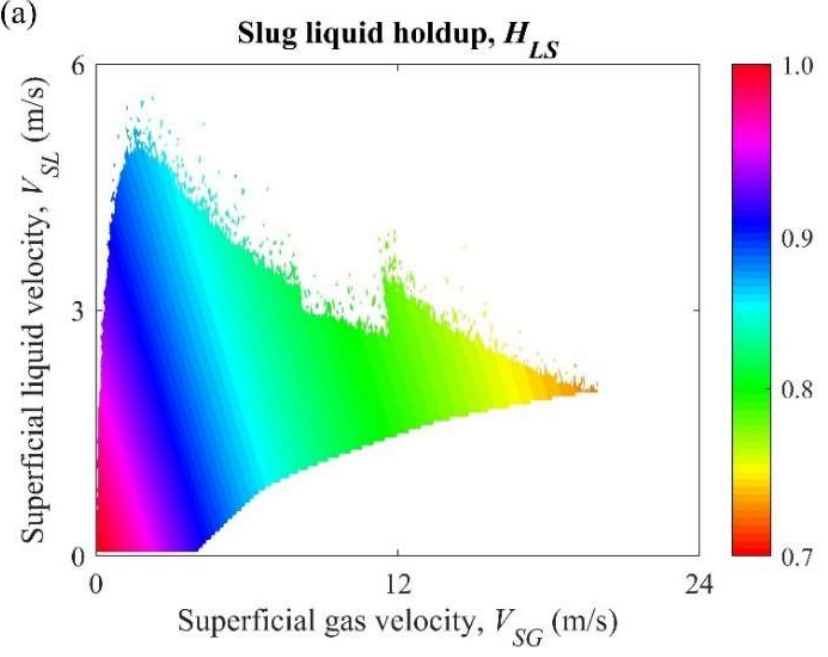

(c) Pressure drop per length, $d P / d L_{u}(\mathrm{kPa} / \mathrm{m})$

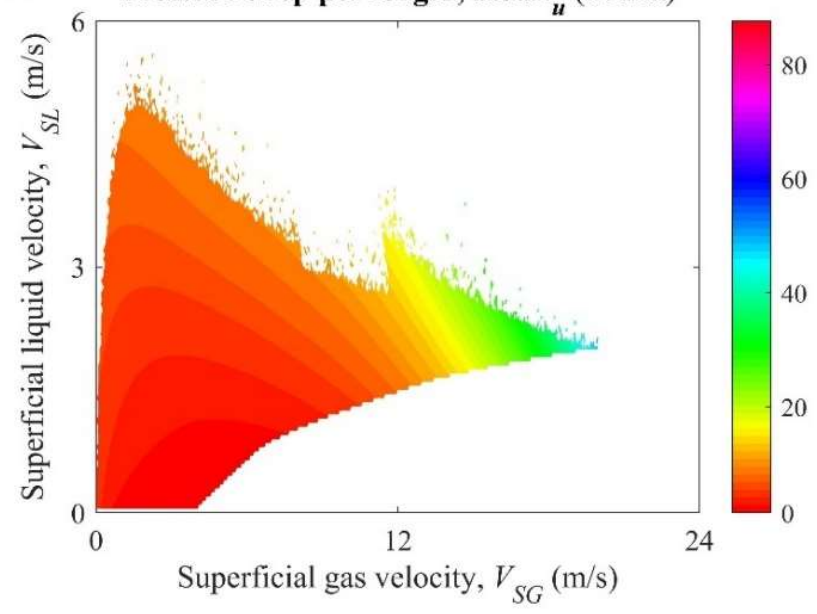

(b)

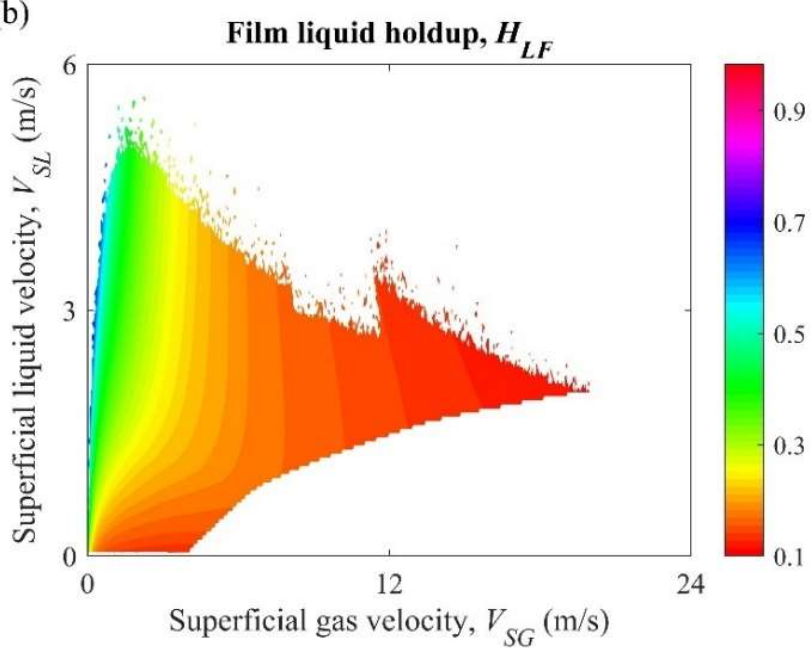

(d)

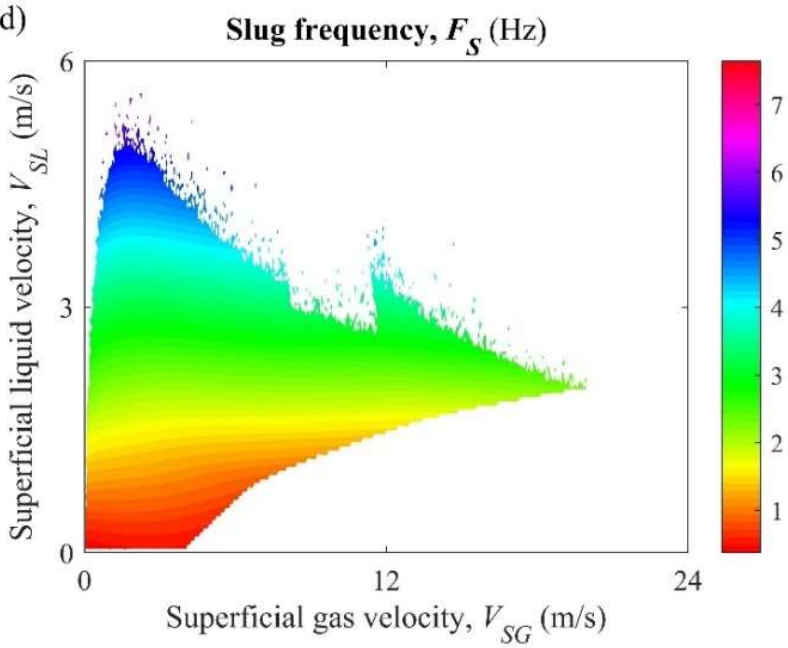

FIGURE 6: VARIATION OF SLUG FLOW CHARACTERISTICS PREDICTED FOR DIAMETER OF 0.05 M AND INCLINATION OF 45 DEGREES USING CLOSURES $\{4,1,2,10\}$ : (A) SLUG LIQUID HOLDUP, (B) FILM LIQUID HOLDUP, (C) PRESSURE DROP PER SLUG UNIT LENGTH, AND (D) SLUG FREQUENCY

[10] Brill, J. P., Schmidt, Z., Coberly, W. A., Herring, J. D., $\&$ Moore, D. W. (1981). Analysis of two-phase tests in largediameter flow lines in Prudhoe Bay field. SPE Journal, 21(03), 363-378.

[11] Brustur, A. G. (2014). Multiphase flow in pipelines: An analysis of the influence of empirical correlations on mechanistic models (MSc thesis, Curtin University).

[12] Fan, Y. (2005). An investigation of low liquid loading gas-liquid stratified flow in near-horizontal pipes. (PhD thesis, University of Tulsa).

[13] Dukler, A. E., \& Hubbard, M. G. (1975). A model for gas-liquid slug flow in horizontal and near horizontal tubes. Industrial \& Engineering Chemistry Fundamentals, 14(4), 337-347.

[14] Felizola, H. (1992). Slug flow in extended reach directional wells. (MSc thesis, University of Tulsa).

[15] Felizola, H., \& Shoham, O. (1995). A unified model for slug flow in upward inclined pipes. ASME, 7-12.

[16] Ferschneider, G. (1983). Ecoulements diphasique gazliquide a poches et a bouchons en conduites. Rev. Inst. Fr. Pét., $38(2), 153-182$.

[17] Gomez, L. E., Shoham, O., Schmidt, Z., Chokshi, R. N., $\&$ Northug, T. (2000). Unified mechanistic model for steadystate two-phase flow: horizontal to vertical upward flow. SPE Journal, 5(03), 339-350.

[18] Gordon, I. C , and Fairhurst, C. P. (1987). Multi-Phase Pipeline and Equipment Design for Marginal and Deep Water Field Development. In Proceedings of the 3rd International Conference on Multi-Phase Flow, Paper Al, The Hague, Netherlands.

[19] Gregory, G. A., Nicholson, M. K., \& Aziz, K. (1978). Correlation of the liquid volume fraction in the slug for horizontal gas-liquid slug flow. International Journal of Multiphase Flow, 4(1), 33-39. 
[20] Grolman, E., Fortuin, J.M.H. (1997). Gas-liquid flow in slightly inclined pipes. Chemical Engineering Science, 52(24), 4461-4471.

[21] Guidance for the Avoidance of Vibration Induced Fatigue Failure in Process Pipework, Energy Institute, London, $1^{\text {st }}$ edition, 2018.

[22] Hart, J., Hamersma, P.J., Fortuin, J.M.H. (1989). Correlations predicting frictional pressure drop and liquid holdup during horizontal gas-liquid pipe flow with a small liquid holdup. International Journal of Multiphase Flow, 15(6), 947964.

[23] Kokal, S. L., \& Stanislav, J. F. (1989). An experimental study of two-phase flow in slightly inclined pipes-I. Flow patterns. Chemical Engineering Science, 44(3), 665-679.

[24] Kora, C., Sarica, C., Zhang, H. Q., Al-Sarkhi, A., \& AlSafran, E. (2011). Effects of high oil viscosity on slug liquid holdup in horizontal pipes. In Canadian Unconventional Resources Conference. SPE.

[25] Ma, B. \& Srinil, N. (2020) "Planar dynamics of inclined curved flexible riser carrying slug liquid-gas flows" Journal of Fluids and Structures 94, 102911.

[26] Malnes, D. (1987). Slug flow in vertical, horizontal and inclined pipes. (Report, Institutt for Energiteknikk).

[27] Marcano, R., Chen, X.T., Sarica, C., Brill J.P. (1998). A study of slug characteristics for two-phase horizontal flow. In International Petroleum Conference and Exhibition of Mexico, SPE.

[28] Meng, W. (1999). Low liquid gas-liquid two-phase flow in near-horizontal pipes. ( $\mathrm{PhD}$ thesis, University of Tulsa).

[29] Mohammadi, S., Papa, M., Pereyra, E., \& Sarica, C. (2019). Genetic algorithm to select a set of closure relationships in multiphase flow models. Journal of Petroleum Science and Engineering, 181, 106224.

[30] Mohmmed, A.O., Al-Kayiem, H.H., Nasif M.S., Time, R.W. (2019). Effect of slug flow frequency on the mechanical streess behaviour of pipelines. International Journal of Pressure Vessels and Piping, 172, 1-9.

[31] Nicholson, M. K., Aziz, K., \& Gregory, G. A. (1978). Intermittent two phase flow in horizontal pipes: predictive models. The Canadian Journal of chemical engineering, 56(6), 653-663.

[32] Nicklin, D. J. (1962). Two-phase bubble flow. Chemical Engineering Science, 17(9), 693-702.

[33] Norris, L. (1982). Correlation of Prudhoe Bay Liquid Slug Lengths and Holdups Including 1981 Large Diameter Flowline Tests. (Internal Report, Exxon Production Research Co).

[34] Petalas, N., \& Aziz, K. (1998). A Mechanistic Model for Multiphase Flow in Pipes. CIM98-39. In Proceedings, 49th Annual Technical Meeting of the Petroleum Society of the CIM, Calgary, Alberta, Canada.

[35] Rodrigues, H., Morales, R., Mazza, R., Rosa, E. (2007) A comparative study of closure equations for gas-liquid slug flow. In Proceedings of COBEM, Brasilia, Brasil.

[36] Roullier, D., Shippen, M., Adames, P., Pereyra, E., \& Sarica, C. (2017). Identification of Optimum Closure
Relationships for a Mechanistic Model Using a Data Set From a Low-Liquid Loading Subsea Pipeline. In Annual Technical Conference and Exhibition, SPE.

[37] Roumazeilles, P. (1994). An experimental study of downward slug flow in inclined pipes (MSc thesis, University of Tulsa).

[38] Scott, S.L., Shoham, O., Brill, J.P. (1989). Predition of slug length in horizontal, large-diameter pipes. SPE Production Engineering, 4(03), 335-340.

[39] Taitel, Y., \& Barnea, D. (1990). A consistent approach for calculating pressure drop in inclined slug flow. Chemical engineering science, 45(5), 1199-1206.

[40] Théron, B. (1989). Ecoulements diphasiques instationnaires en conduite horizontale ( $\mathrm{PhD}$ thesis, INPT).

[41] Zanganeh, H., Kurushina, V., Srinil, N. iSLUG identification of steady slug flow characteristics. DOI: 10.25405/data.ncl.10006901.

[42] Zhang, H. Q., Jayawardena, S. S., Redus, C. L., \& Brill, J. P. (2000). Slug dynamics in gas-liquid pipe flow. Journal of Energy Resources Technology, 122(1), 14-21.

[43] Zhang, H. Q., Wang, Q., Sarica, C., \& Brill, J. P. (2003). Unified model for gas-liquid pipe flow via slug dynamics - Part 1: Model development. Journal of Energy Resources Technology, 125(4), 266-273. 